\title{
A Use of New Questionnaire Based Tool for Evaluation of Medical Student's Satisfaction Regarding Their Final Professorial Surgical Appointment at Faculty of Medicine, University of Ruhuna, Sri Lanka
}

\author{
Kumara M. M. A. J. ${ }^{1}$, Seneviratne R. W. ${ }^{1}$, Abewickrama R. ${ }^{1}$, Kumarasingha J. P. M. ${ }^{1}$, \\ De Silva P. $\mathbf{~}^{2}$ \\ ${ }^{1}$ Department of Surgery, Faculty of Medicine, University of Ruhuna, Galle, Sri Lanka \\ ${ }^{2}$ Department of Community Medicine, Faculty of Medicine, University of Ruhuna, Galle, Sri Lanka
}

Email address:

ranjanamst@yahoo.com (Kumara M. M. A. J.)

To cite this article:

Kumara M. M. A. J., Seneviratne R. W., Abewickrama R., Kumarasingha J. P. M., De Silva P. V.. A Use of New Questionnaire Based Tool for Evaluation of Medical Student's Satisfaction Regarding Their Final Professorial Surgical Appointment at Faculty of Medicine, University of Ruhuna, Sri Lanka. European Journal of Preventive Medicine. Special Issue: New Frontiers of Public Health from the Pearl of Indian Ocean, Sri Lanka. Vol. 3, No. 2-1, 2015, pp. 50-53. doi: 10.11648/j.ejpm.s.2015030201.19

\begin{abstract}
Introduction: Faculty of Medicine University of Ruhuna, Located in southern coastal town of Galle is one of 10 state owned medical faculties in Sri Lanka. . Surgical curriculum consist of lectures, Tutorials, ward classes as well as clinical appointments scattered through last 3 years. The Final year two-month professorial surgical appointment is meant to ensure that Graduates have acquired rounded knowledge and key skills in surgery to pass out to become safe and competent intern house officers. No formal study has been conducted to assess the student perspectives regarding this appointment. Methodology: Purpose of this study is to evaluate the student component of the 360 degree assessment regarding the effectiveness of teaching programme of professorial surgical clinical appointment using a questionnaire consist of five components. Results: Vast majority of students answered the questionnaire (range 130-136 except concerning requirement to modify end appointment assessment method when responding number fell to 118). Components $\mathrm{A}$ is aimed to evaluate students view of professorial appointment and its usefulness for different components of final MBBS examination .Over $84 \%$ marked generally useful and above for all the components of final MBBS examination. Highest was for short cases at $96.1 \%$ while lowest figures were for long cases (84.4\%). Component B is to assess view of different modalities of clinical teaching encounters during professorial appointment and its usefulness for improving surgical knowledge and a good pass at final mbbs. $97.8 \%$ thought elective ward rounds were generally useful or above while lowest was obtained by emergency theatre teaching (84\%). Component $\mathrm{C}$ has six questions aimed to assess student satisfaction of quantity of particular sessions. $89.3 \%$ were satisfied about number of clinic teaching sessions which fell towards short case practice sessions (73.8\%), theatre teaching sessions (59.2\%) and endoscopy sessions (58.9\%). D is a single question about their satisfaction of end appointment assessment method and any modifications required.46.5\% thought continuous assessment method require modifications. Component E assesses the overall effectiveness of the surgery appointment in functioning as an intern medical officer effectively. 81.8\% marked generally useful and above. Conclusions: Significant majority of students were satisfied in most of the components of final year professorial appointment while certain drawbacks became apparent such as insufficient number of endoscopic and Operating Theatre sessions. The designed Performa appears to be a satisfactory tool to assess student satisfaction about a final year professorial clinical appointment and more studies and further modifications may result in its validation even for other clinical appointments.
\end{abstract}

Keywords: Student satisfaction, surgical professorial appointment, university of Ruhuna

\section{Introduction}

Faculty of Medicine, University of Ruhuna, located in southern coastal town of Galle is one of 10 state owned medical faculties in Sri Lanka.Annual Intake is approximately 150 students. Student selection is based on merit criteria 
employed by university grant commission of Sri Lanka as well as the student preference. The faculty runs a five year traditional curriculum with preclinical, para-clinical and clinical components with some recent modifications. Clinical component is divided into five subjects namely Surgery, Medicine, Paediatrics, Gynaecology \& Obstetrics and Psychiatry. Surgical curriculum consist of lectures, Tutorials, ward classes as well as clinical appointments scattered through last 3 years. Latter consist of two two-month clinical appointments in General surgery, two week appointments in ENT,Radiology, Anesthesia, Ophthalmology, Oncologyand general and one month appointment in Orthopaedics. This culminates in final year two month surgical appointment at professorial surgical unit, Teaching Hospital, Karapitiya, Galle. Final year batch is divided in to five groups who do the appointments in rotation making each group size approximately 30. Students face an end appointment assessment which carries marks to final examination.

Justification

Final year professorial surgical appointment is meant to ensure that Graduates have acquired rounded knowledge and key skills in surgery to pass out as safe and competent intern house Officers. No formal study has been conducted to assess the student perspectives regarding this appointment.

Purpose of this study is to evaluate the student component of the 360 degree assessment regarding the effectiveness of teaching programme of professorial surgical clinical appointment using a simple questionnaire. This form of summative assessment will allow both teachers and students to identify defects in curriculum as well as strengths and weaknesses of the teaching programme. Periodic assessment regarding students satisfaction of different aspects of clinical surgical appointment will not only improve quality of experience but also enhance attraction of the field as future career(1)

\section{Methodology}

A questioners was designed consist of three components A, $\mathrm{B}, \mathrm{C}$ and two special questions $\mathrm{D}$ and E.It consist of open close ended questions to help standardization of responses as well as the evaluation process and open ended questions to allow room for original remarks which are of qualitative value.

Components A aimed to evaluate students view of professorial appointment and its usefulness for different components of final MBBS examination. Six questions to check MCQ, SBA, Essay, Long case, short case were incorporated with five scale student responses ranging from not useful to extremely useful.

Components B aimed to evaluate student's view of different modalities of clinical teaching encounters during professorial appointment and its usefulness for improving surgical knowledge and a good pass at final MBBS.This consist of ten questions covering Elective ward round teaching, emergency ward round teaching, elective ward class teaching, emergency ward class teaching, Elective theatre teaching, Emergency theatre teaching, endoscopy list teaching, clinic teaching, short cases practice at clinics and end appointment assessment.

Component $\mathrm{C}$ has six questions aimed to assess student's satisfaction of quantity of particular sessions.Sessions assessed include numbers of ward rounds (emergency and elective), wardclasses (emergency and elective), theatre teaching sessions (emergency and elective), endoscopy teaching sessions, clinic teaching sessions and short case practice sessions.

Component $\mathrm{D}$ is a single question about their satisfaction of end appointment assessment method and any modifications suggested.

Component $\mathrm{E}$ assess the overall effectiveness of the surgery appointment in functioning as an intern medical officer effectively.

While component $\mathrm{D}$ and $\mathrm{E}$ had dichotomous responses other components were evaluated on 5 point scale both widely recognized evaluation methods.

This anonymous questionnaire was distributed among students on the last day of their Professorial surgical appointment and collected after one hour of senior lecturer supervised answering in order to ensure that their answers are independent. Monitor of the group collected papers afterwards to ensure the senior lecturer does not have glimpse about particular student and his paper. Purpose and procedure were explained to students before hand and they were instructed to avoid answering the entire questionnaire, any question or part of questionif they wish to do so.

\section{Results}

In responding to their satisfaction regarding evaluation of final year surgical appointment with regards to components of the final MBBS examination vast majority of students answered the questionnaire (range 130-136 except concerning requirement to modify end appointment assessment method when responding number fell to 118).

Table 1. Component A Usefulness of final year professorial surgical appointment with regards to components of the final MBBS examination.

\begin{tabular}{|c|c|c|c|c|c|c|c|c|c|c|c|}
\hline $\begin{array}{l}\text { Question } \\
\text { No. }\end{array}$ & $\begin{array}{l}\text { Total no. of } \\
\text { respond }\end{array}$ & $\begin{array}{l}\text { Not } \\
\text { Useful }\end{array}$ & $\%$ & $\begin{array}{l}2 \text { Some what } \\
\text { useful }\end{array}$ & $\%$ & $\begin{array}{l}3 \text { Generally } \\
\text { useful }\end{array}$ & $\%$ & $\begin{array}{l}4 \text { Very } \\
\text { useful }\end{array}$ & $\%$ & $\begin{array}{l}5 \text { Extremely } \\
\text { Useful }\end{array}$ & $\%$ \\
\hline MCQ & 136 & 2 & 1.50 & 10 & 7.35 & 35 & 26.00 & 55 & 40.00 & 34 & 25.00 \\
\hline SBA & 133 & 2 & 1.50 & 16 & 12.00 & 34 & 26.00 & 48 & 36.00 & 33 & 24.80 \\
\hline ESSEY & 130 & 3 & 2.30 & 13 & 10.00 & 44 & 34.00 & 54 & 42.00 & 16 & 12.30 \\
\hline $\begin{array}{l}\text { LONG } \\
\text { CASE }\end{array}$ & 134 & 3 & 2.20 & 14 & 10.40 & 46 & 34.00 & 49 & 37.00 & 22 & 16.40 \\
\hline $\begin{array}{l}\text { SHORT } \\
\text { CASES }\end{array}$ & 135 & 1 & 0.70 & 4 & 2.96 & 12 & 8.90 & 68 & 50.00 & 50 & 37.00 \\
\hline VIVA & 134 & 1 & 0.70 & 7 & 5.22 & 40 & 30.00 & 53 & 40.00 & 33 & 24.60 \\
\hline
\end{tabular}


98.5\%(124) marked Generally useful and above for usefulness on MCQ component while their responses were distributed as $25.7 \%, 40.4 \%$ and $25 \%$ along ascending order of generally useful, very useful and extremely useful. $86.5 \%$ thought generally useful and above for SBA component with 25.6, 36.1 and 24.8 distribution along ascending order. $89 \%$ thought it as GU and above for essays with $33.8 \%, 41.5 \%$ $12.3 \%$ distribution. For long cases it was $84.4 \%$ breaking down to $34.3 \%, 36.6 \%$ and $16.4 \%$ while figures for short cases were $96.3 \%$ breaking down to $8.9 \% 50.4 \%$ and $37 \%$. (94.1\% thought the appointment was generally useful and above for viva breaking down to $29.9 \%, 39.6 \%$ and $24.6 \%$.

Table 2. Component B Usefulness of different clinical encounters with regard to improving surgical knowledge and achieving good pass in the final MBBS.

\begin{tabular}{|c|c|c|c|c|c|c|c|c|c|c|c|}
\hline & $\begin{array}{l}\text { Total no. of respond } \\
\text { of this question }\end{array}$ & $\begin{array}{l}\text { Not } \\
\text { useful }\end{array}$ & $\%$ & $\begin{array}{l}\text { Somewhat } \\
\text { useful }\end{array}$ & $\%$ & $\begin{array}{l}\text { Generally } \\
\text { useful }\end{array}$ & $\%$ & $\begin{array}{l}\text { Very } \\
\text { useful }\end{array}$ & $\%$ & $\begin{array}{l}\text { Extremely } \\
\text { useful }\end{array}$ & $\%$ \\
\hline $\begin{array}{l}\text { Elective ward round } \\
\text { teaching }\end{array}$ & 136 & & 0.00 & 3 & 2.20 & 31 & 22.79 & 63 & 46.32 & 39 & 28.67 \\
\hline $\begin{array}{l}\text { Emergency ward } \\
\text { round teaching }\end{array}$ & 133 & 4 & 3.00 & 14 & 10.52 & 39 & 29.32 & 49 & 36.84 & 27 & 20.30 \\
\hline $\begin{array}{l}\text { Elective ward class } \\
\text { teaching }\end{array}$ & 134 & 1 & 0.75 & 7 & 5.22 & 40 & 29.85 & 55 & 41.04 & 31 & 23.13 \\
\hline $\begin{array}{l}\text { Emergency ward class } \\
\text { teaching }\end{array}$ & 125 & 3 & 2.40 & 10 & 8.00 & 40 & 32.00 & 47 & 37.60 & 25 & 20.00 \\
\hline $\begin{array}{l}\text { Elective theatre } \\
\text { teaching }\end{array}$ & 128 & & 0.00 & 14 & 10.93 & 47 & 36.71 & 47 & 36.71 & 20 & 15.62 \\
\hline $\begin{array}{l}\text { Emergency Theatre } \\
\text { teaching }\end{array}$ & 125 & 2 & 1.60 & 18 & 14.40 & 41 & 32.80 & 43 & 34.40 & 21 & 16.80 \\
\hline Endoscopy teaching & 126 & 5 & 3.96 & 11 & 8.73 & 42 & 33.33 & 52 & 41.26 & 16 & 12.69 \\
\hline Clinic teaching & 135 & & 0.00 & 2 & 1.48 & 20 & 14.81 & 57 & 42.22 & 56 & 41.48 \\
\hline $\begin{array}{l}\text { Clinic short case } \\
\text { performance } \\
\text { assessment }\end{array}$ & 131 & & 0.00 & 6 & 4.58 & 16 & 12.21 & 45 & 34.35 & 64 & 48.85 \\
\hline $\begin{array}{l}\text { Continuous } \\
\text { assessment }\end{array}$ & 128 & 5 & 3.90 & 12 & 9.37 & 37 & 28.90 & 51 & 39.84 & 23 & 17.96 \\
\hline
\end{tabular}

In evaluating usefulness of different clinical encounters with regard to improving surgical knowledge and achieving a good pass in the final MBBS majority of students responded (range 125-136). 97.8\% thought elective ward rounds were generally useful or above. $46.3 \%$ thought them as very useful and $28.7 \%$ extremely useful. Figures for emergency ward rounds were $86.5 \%, 36.8 \%$ and $20.3 \%$. Elective ward classes scored $94.1 \%$ with $41 \%$ marking very useful and $23.1 \%$ generally useful while figures for emergency ward classes were $87.6 \%, 37.6 \%$ and $20 \%$. Elective theatre teaching recorded $89.1 \%$ as useful with $36.7 \%$ generally useful and
$15.6 \%$ extremely useful. Figures for emergency theatre teaching was $84 \%, 34.4 \%$ and $12.7 \% .87 .3 \%$ marked endoscopy teaching as generally useful or above breaking down in to $33.3 \%, 41.3 \%$ and $12.7 \%$ along lines of generally useful, very useful and extremely useful. Figures for clinic teaching were $98.5 \%$ breaking in to $14.8 \%, 42.2 \%$ and $41.5 \%$ while those for clinic short case teaching was $95.4 \%$ breaking to $12.2 \%, 34.4 \%$ and $48.9 \%$. $86.3 \%$ marked Continuous assessment as generally useful and above which $28.9 \%$ thought generally useful and $39.8 \%$ thought very useful.

Table 3. component C Overall quantitative assessment.

\begin{tabular}{|c|c|c|c|c|c|}
\hline & $\begin{array}{l}\text { Total no. of respond } \\
\text { of this Question }\end{array}$ & Not Adequate & $\%$ & Adequate & $\%$ \\
\hline $\begin{array}{l}\text { Number of ward round(emergency and } \\
\text { elective) teaching sessions }\end{array}$ & 128 & 32 & 25.00 & 96 & 75.00 \\
\hline $\begin{array}{l}\text { Number of ward class(emergency and } \\
\text { elective ) teaching sessions }\end{array}$ & 128 & 50 & 39.10 & 78 & 60.90 \\
\hline $\begin{array}{l}\text { Number of theatre (emergency and elective ) } \\
\text { teaching sessions }\end{array}$ & 129 & 53 & 41.10 & 76 & 58.90 \\
\hline Number of clinic teaching sessions & 121 & 13 & 10.70 & 108 & 89.30 \\
\hline Number of clinic short case practice sessions & 121 & 32 & 26.40 & 89 & 73.60 \\
\hline
\end{tabular}

In assessing overall volume of teaching encounters for obtaining adequate knowledge in surgery for final MBBS significant majority responded (Range 122-136).75\% thought number of ward rounds were adequate and $61.2 \%$ thought that of ward classes were adequate. 59.2\% though number of teaching theatre sessions were adequate and $58.9 \%$ thought number of endoscopy sessions was adequate. $89.3 \%$ were satisfied about number of clinic teaching sessions and $73.8 \%$ about short case practice sessions.

$53.8 \%(63 / 117)$ thought continuous assessment method requires modifications when assessed as component $\mathrm{D}$.

When inquired about effectiveness of Final year 
professorial appointment in giving the confidence to practice as intern house officers in component $\mathrm{E}$ the percentage distribution was 3.31(not effective), 14.9(somewhat effective), 43(generally effective), 25.6 (very effective)and 13.2 (extremely effective) among 121 responders.

\section{Discussion}

Evaluation of a clinical appointment from medical student's perspective is an important component of the 360 degree assessment of academic programme. However this specific component is rarely evaluated per se and validated tools for such are difficult to find. This study is aimed to introduce a reasonably effective tool in the form of ananonymous performa completed by individual students is an attempt to fill this void in assessment.This will be of no point value which is recommended for summative assessment. Existence of gaps over student expectations of many different aspects in teaching-learning encounters employed need to be addressed to prevent dissatisfaction (2).

The fact that vast majority of students responding to the performa enhances the validity of findings.Above $84 \%$ thought the appointment as useful to all the components of the final MB examination. Highest positives for categories generally useful and above were obtained by Shortcases $(96.3 \%)$ while long cases got the lowest figure of $84.4 \%$.This is a reflection of rounded nature, high quality and relevance of final year professorial surgical appointment to the academic end goal.

Comparing value of different teaching encounters to improve surgical knowledge and achieving a good pass in final MBBS, the broader objective, over $84 \%$ marked generally useful and above for all components.98.5\% thought clinic teaching sessions were generally useful and above. $41.5 \%$ thought of them as extremely useful and $34.4 \%$ as very useful. Figures for clinic short case teaching are as equally good at $95.4 \%, 48.9 \%$ and $34.4 \%$ respectively. Elective ward round teaching figures were similar at $97.8 \%$, $28.7 \%$ and $46 \%$.Lowest figure was $84.5 \%$ scoring above generally useful was obtained by emergency theatre teaching where busy schedules and acuteness of situation may affect teaching.

In overall assessment it is clear that majority of students were satisfied about number of clinic teaching sessions $(89.3 \%)$, number of short case practice sessions $(73.8 \%)$ and number of ward rounds (75.4\%). Figures for number of endoscopy sessions, theatres and ward classes were significantly low at $58.9 \%, 59.2 \%$ and $61 \%$.Clinic teaching where short case teaching is most frequently performed happens concurrently with 4 consultants dividing the group among them leading to staff student ration of 1:7 the optimum for university academic work. Professorial Unit manned by 4 surgeons get the same number of OT sessions and endoscopy sessions as any single consultant unit in the hospital and this is clearly inadequate which affect effectiveness of student learning. Only 3-5 students can go in to theatre or endoscopy room at a given time due to limitations of safety margin, sterility and space which hampers the training of majority. More elective and emergency theatre sessions and Endoscopy sessions if obtained,are likely to improve this situation. It also appears that although ward round teaching is satisfactory ward classes are not taken often probably due to time limitations.

$46 \%$ of students a marginal minority like the format of end appointment assessment changed. This is usually conducted in the form of vivas with students are interviewed by each of the five consultants ( 4 surgeons and the anesthetist) in the departments. A new more structured viva or a different more objective format may be beneficial.

$81.8 \%$ marked generally useful and above for the effectiveness of appointment to function efficiently as an intern medical officer with $52 \%$ marking at generally useful. Although this is acceptable measures are required to enhance their confidence in previously identified deficient areas.

\section{Conclusions}

Relevance of the final year professorial appointment for its objectives of improving surgical knowledge, addressing different components of the surgical final MBBS and preparing them to become intern house officers appears to be satisfactory. Clinic teaching including short case practices done where students are exposed regularly with optimum staff: student ratio is most appreciated by students. This is a welcome finding when psychomotor domain skills are found most wanting in many undergraduate training programmes(3). Number of theater and endoscopy lists and ward classes taken need increasing while end appointment assessment method need a significant modification probably in a more objective direction. Ward classes can be takento cover preplanned list of long cases rather than teaching any cases which come along (3).

The designed Performa appears to be a satisfactory tool to assess student satisfaction about a final yearprofessorial clinical appointment and more studies and further modification may result in its validation even for other clinical appointments.

\section{References}

[1] Ekenze SO, Ugwumba FO, Obi UM, Ekenze OS. Undergraduate surgery clerkship and the choice of surgery as a career: perspective from a developing country. World J Surg. 2013 Sep: 37(9):2094-100.

[2] BahramNabilou, DavoudKhorasani-Zavareh. The Bridge Between Real and Ideal: Students Perception on Quality Gap in Reality and Their Educational Expectations. Iran Red Crescent Med J. 2014 Sep: 16(9): e14254.

[3] Charles J, Kalpana S, Max LJS, Shantharam D. A Cross Sectional Study on Domain Based Evaluation of Medical Students at the Tamil Nadu Dr.M.G.R. Medical University-A Success.Journal of Research \& Method in Education (IOSRJRME).2014:4(4):33-36. 